\title{
COLD FUSION ON THE BASIS OF THE MODEL OF THE PLANET EARTH
}

\author{
Tarassenko G.V., Tarassenko M.G. \\ Caspian State university of technologies and engineering named after Sh. Yesenov, \\ Kazakhstan
}

Cold fusion is not possible in atmospheric conditions but it is possible underground. Synthesis formation is connected with electricity in the entrails of the earth. Electricity is produced with the help of friction and geospheres speed differential from the core $(20-40 \mathrm{~m} / \mathrm{s}$ to the surface), the speed of which according to GPS data is $2-16 \mathrm{~cm}$ per year. Faraday has determined planet electric capacity with 1 farad. Continent drift takes place at the expense of geospheres rotation, leading to subduction of ocean and continental plates, abduction, spreading, rifting and collision. An example of planet formation is ball concretions. Their formation in the layers-collectors is connected with ball and linear lightning, formed with the help of electric discharge (short circuit) that attract various rocks from layers' fluids. In this connection concretions consist of several geospheres with different chemical composition from the core to the surface and the core is usually hollow or very soft. This can be connected with the fact that lightning plasma loses energy and fluid rotation stops. The Earth has the same structure where there is plasm in the core and gas dust cloud from the moment of the Earth origin. Its rotation produces dynamo effect of the planet Earth that creates gravitation and magnetic field of the Earth and has been existing for 4,5 billion years already. Such point of view of the model of the planet Earth explains many natural processes in the Earth's crust. It consists of natural electric condenser and heater, the cavities of which are filled with fluid formed in the zones of subduction with the help of the Earth electricity and cold fusion, oil is made of organic and water of non-organic. Various coal deposits are formed of those plates' fluid which originated from oil with the help of cold fusion and iron ores, absorbed from plates' waters. So electricity is necessary to produce oil, it produces pressure and temperature in subduction zones and their migration produces radiator effect for cooling and lubricating geospheres rotation. Spheres rotation leads to plates' friction with each other and produces millstone effect that grind the rock into powder. Rocks are dissolved in plates waters and are taken for tens of kilometers on laterals and verticals, filling karsts and forming basal benches of nonsoluble rocks (millstone, conglomerate, bennet) forming layers of collector and secondary deposits. Concretions formations take place in them with the help of lightning underground. Volcanos formation is connected with the Earth electricity (electrical furnace) that melts rocks and forms magma. Electricity availability in volcanos evidence is lightning above volcanos that spin eruption products and ball bombs-concretions. There is no magma under the continents and the planet Earth is cold with the temperature of 600 degrees in the core. Earthquakes are also caused by electric discharge in karsts filled with methane at different depths. Karsts formation increases with depth at the expense of great speed of geosphere, determined on listric snap in lithosphere and mantle, the speed of which increases up to 20 meter per year and more to the core. Spheres are torn and form karsts. That is why seismic reflecting horizons are less expressed and interrupted with depth. The evidence of hydrocarbon formation with the help of cold fusion is based on carrying out experiments with arc discharger at cathode at battery water solution adding titanium powder. After some time after burning arc discharger there was strong smell of acetylene. On the basis of this data, the planet Earth is a constantly functioning mechanism from the moment of "Big Bang". "Big Bang" was formed with the help of electric discharge but not particles (substance) collision. Big hadronic collider is the model of the plant Earth appearance which is not proved by the experiments. For this I have created concretion model of the planet Earth which was formed with the help of electric discharge-explosion on the example of ball concretions formation. Tests on modelling the planet have led me to the design of electric generator, where ball and linear lightings is the rotor. Their rotation in the reactor will provide the stator with the electricity. Generator of the new type will save the planet Earth from destruction because fluids (oil, water) are the blood of the planet and their exhaustion leads to climate global change. Fluids serve the planet to cool and lubricate geospheres rotation. Lithosphere devastation is earth radiator and planet electric condenser destruction that serve for the planet vital activity. Sharp decrease of magnetic and gravitation filed of the Earth is the evidence of concretion model of the planet Earth and its actual model.

\section{The results of analysis of samples of spherical concretions mountains Sherkala}




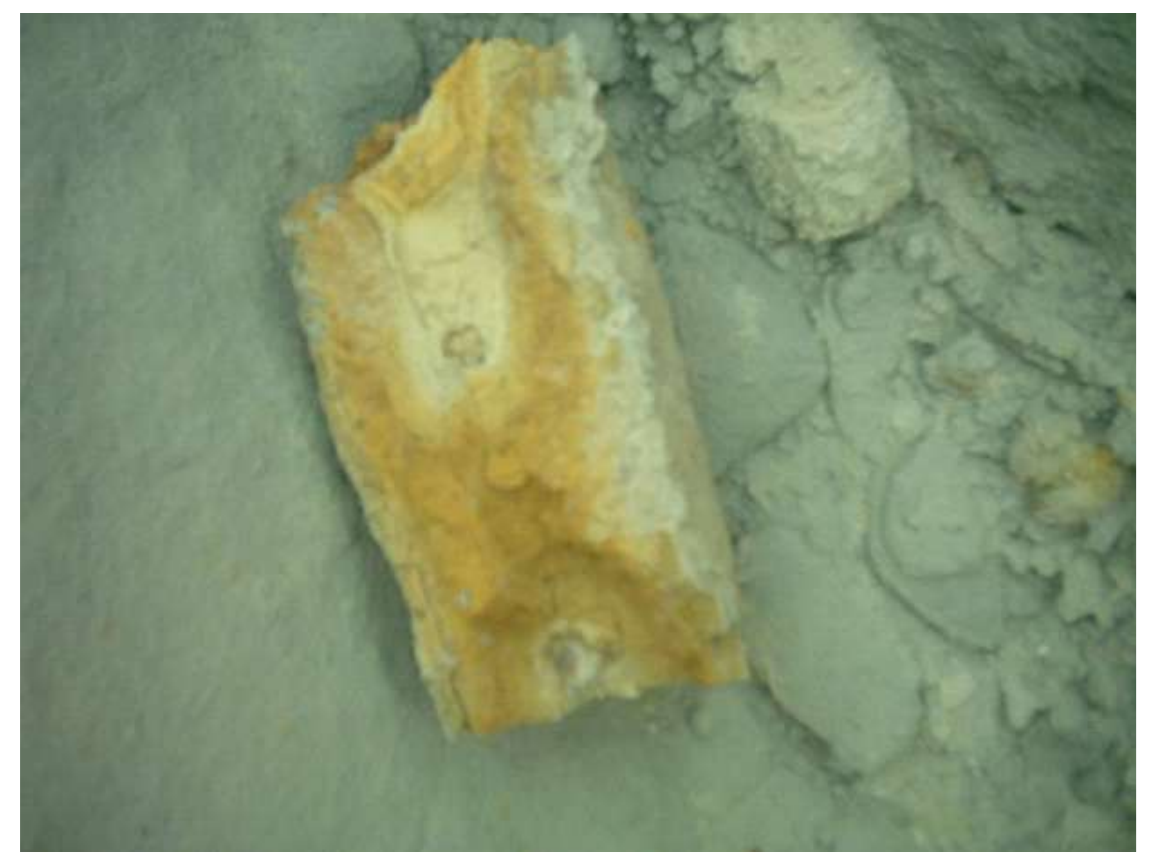

Concretion analysis from such places as Sherkala and Zhingyldy demonstrated the tendency of ferrum accretion in the concretion core. At the same time a lighter element silicium decreases its concentration from outer shells to concretion core. This tendency gives evidence that slow nuclear transformations occur in this formation and core elements composition strives to its more stable condition when ferrum is accumulated in the core and it is more resistant to decomposition. Ferrum has the most energy of nucleon connection in the core more than $8 \mathrm{MeV}$ and for this reason is the final element of both fusion and fission. The table presents energy connections in nucleon in cores of the elements. 


\begin{tabular}{|c|c|c|c|}
\hline \multirow{2}{*}{ Ingredient name, $\%$} & \multicolumn{3}{|c|}{ Assay } \\
\cline { 2 - 4 } & host rock & ball inside the concretion & inside the ball \\
\hline & & & 56,3 \\
$\mathrm{SiO}_{2}$ & 92 & 84,3 & 17,6 \\
$\mathrm{Fe}_{2} \mathrm{O}_{3}$, & 1,2 & 5,5 & 0,0004 \\
$\mathrm{NiO}$, & 0,0012 & - & 0,0005 \\
$\mathrm{ZnO}$, & 0,0007 & 0,0027 & 0,0010 \\
$\mathrm{CuO}$, & 0,0008 & 0,0015 & 0,0028 \\
$\mathrm{PbO}$, & 0,0010 & 0,0018 & 0,0003 \\
$\mathrm{CoO}$, & - & 0,0004 & - \\
$\mathrm{CdO}$, & - & - & 2,7 \\
$\mathrm{SO}_{4}^{2-}$, & 0,47 & 0,28 & - \\
$\mathrm{CO}_{3}^{2-}$, & - & - & 0,3 \\
$\mathrm{CaO}^{2}$ & 0,4 & 0,4 & \\
\hline
\end{tabular}

The results of analysis of samples of spherical concretions Tracts Zhyngyldy

\begin{tabular}{|c|c|c|c|c|}
\hline Ingredient name & & \multirow{3}{*}{586} & & \multirow{2}{*}{$\begin{array}{c}\text { Ball surface } \\
4,6\end{array}$} \\
\hline 1. $\mathrm{Fe}_{2} \mathrm{O}_{3}, \%$ & & & & \\
\hline 2. $\mathrm{SiO}_{2}, \%$ & 80 & & & 75,2 \\
\hline 3. $\mathrm{CaO}, \%$ & & - & 60,8 & - \\
\hline 4. $\mathrm{MgO}, \%$ & - & - & - & - \\
\hline $5 . \mathrm{ZnO}, \%$ & - & 0,29 & - & 0,28 \\
\hline 6. $\mathrm{CoO}, \%$ & $\begin{array}{l}0,42 \\
0,08\end{array}$ & 0,06 & 0,27 & 0,08 \\
\hline 7. $\mathrm{NiO}, \%$ & $\begin{array}{l}0,08 \\
0,56\end{array}$ & 0,42 & 0,06 & 0,58 \\
\hline 8. $\mathrm{PbO}, \%$ & 0,56 & 0,07 & $\begin{array}{l}0,47 \\
0,08\end{array}$ & 0,09 \\
\hline 9. $\mathrm{CuO}, \%$ & 0,11 & 0,012 & $\begin{array}{l}0,08 \\
0,010\end{array}$ & 0,013 \\
\hline 10. $\mathrm{CdO}, \%$ & 0,010 & - & 0,010 & - \\
\hline 11. $\left(\mathrm{SO}_{4}^{2-}\right), \%$ & $0, \overline{76}$ & 0,96 & 1,19 & 1,36 \\
\hline 12. $\left(\mathrm{CO}_{3}{ }^{2-}\right), \%$ & - & - & - & - \\
\hline
\end{tabular}

Ferrum has the most energy of nucleon connection in the core more than $8 \mathrm{MeV}$ and for this reason is the final element of both fusion and fission. The table presents energy connections in nucleon in cores of the elements. 


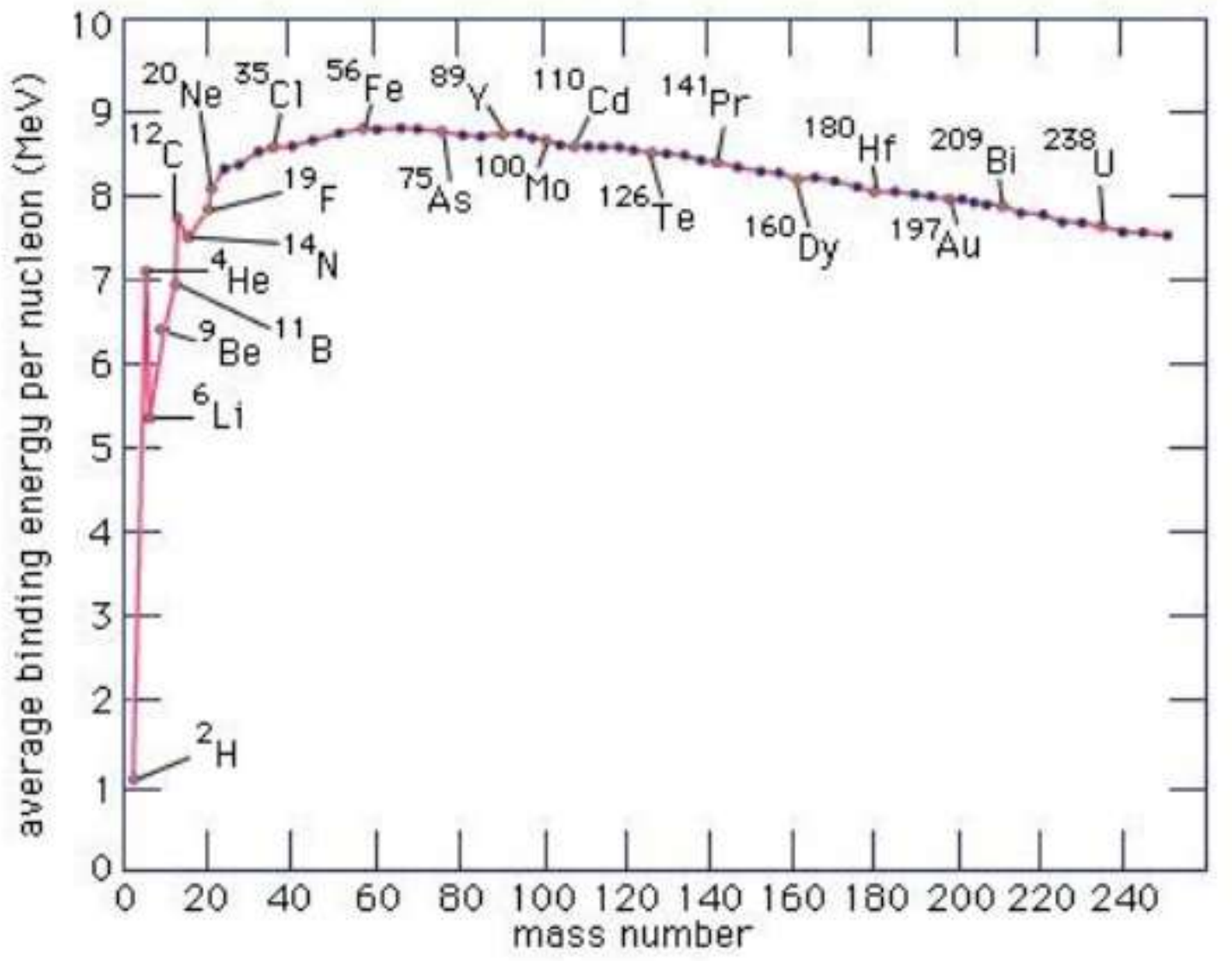

Fusion reaction is more profitable in terms of energy to the left of the ferrum, fission reaction is more profitable in terms of energy to the right of the ferrum. Thus it is supposed that as a result of the conditions in sheet deposits solution (pressure, temperature, electricity, relevant element sheet deposit composition) conditions appeared for low energy nuclear transformations as a result of which light chemical elements gradually converted into heavier ones and were concentrated in the center of the concretion.

The results of analysis of samples of spherical concretions Tracts Onda

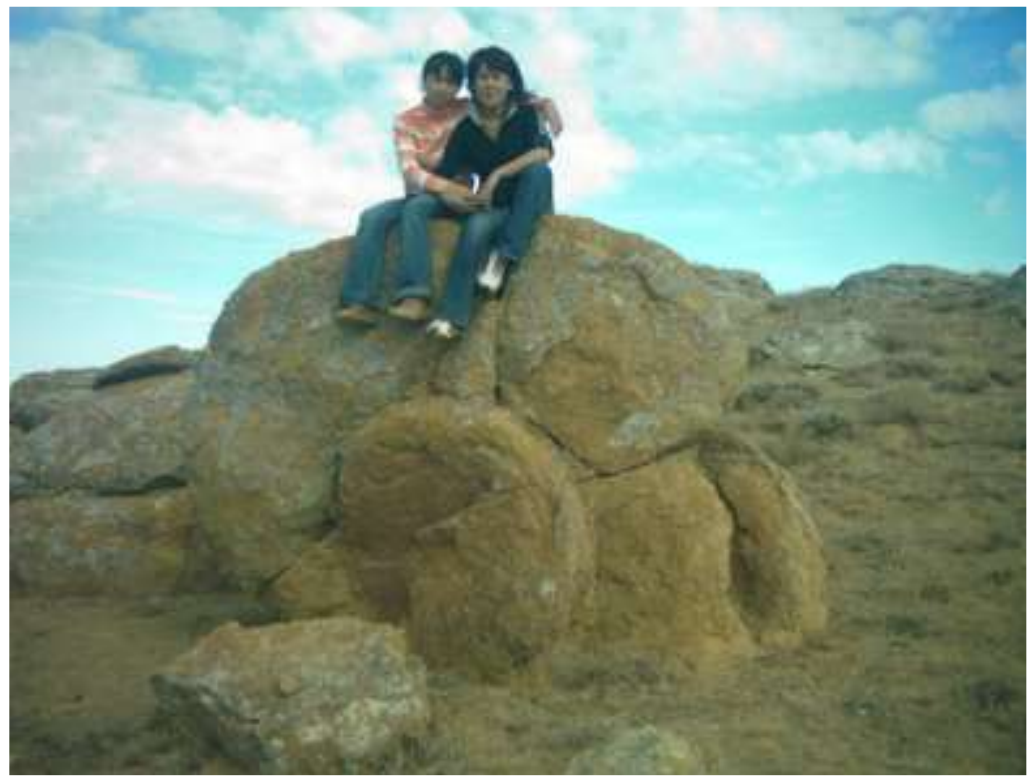




\begin{tabular}{|c|c|c|c|}
\hline \multirow{2}{*}{ Ingredient name, $\%$} & \multicolumn{3}{|c|}{ Assay } \\
\hline & Core (dark part) & Core (light part) & surface of the ball \\
\hline 1. $\mathrm{Fe}_{2} \mathrm{O}_{3}$, & 2,4 & 3,4 & 3,8 \\
\hline 2. $\mathrm{NiO}$ & 0,0036 & 0,0035 & 0,0037 \\
\hline 3. $\mathrm{ZnO}$ & 0,0047 & 0,0038 & 0,0044 \\
\hline 4. $\mathrm{CuO}$, & 0,0053 & 0,0038 & 0,0046 \\
\hline 5. $\mathrm{PbO}$ & 0,0038 & 0,0037 & 0,0037 \\
\hline 6. $\mathrm{CoO}$, & 0,0028 & 0,0028 & 0,0030 \\
\hline 7. $\mathrm{CO}_{3}{ }^{2-}$ & 31,5 & 27,1 & 34,8 \\
\hline 8. $\mathrm{CaO}$, & 50,5 & 52,5 & 53,3 \\
\hline 9. $\mathrm{SiO}_{2}$ & 39,1 & 38,1 & 36,6 \\
\hline
\end{tabular}

The results of the analysis of some concretions in the place of Ondy do not confirm the hypothesis; here there are similar ferrum concentration in the core, middle and outer shells if the ball. Supposedly, there are concretions where there are no conditions for cold fusion. Unfortunately, statistics of the experimental data does not prove the hypothesis of nuclear transformations in the Earth layers but our research is only at the beginning stage. We are going to accumulate and analyze the date to receive more certain results.

Appendix in 3 pages spectrum and chemical analysis of the assays № 1 № 1, 2, 3

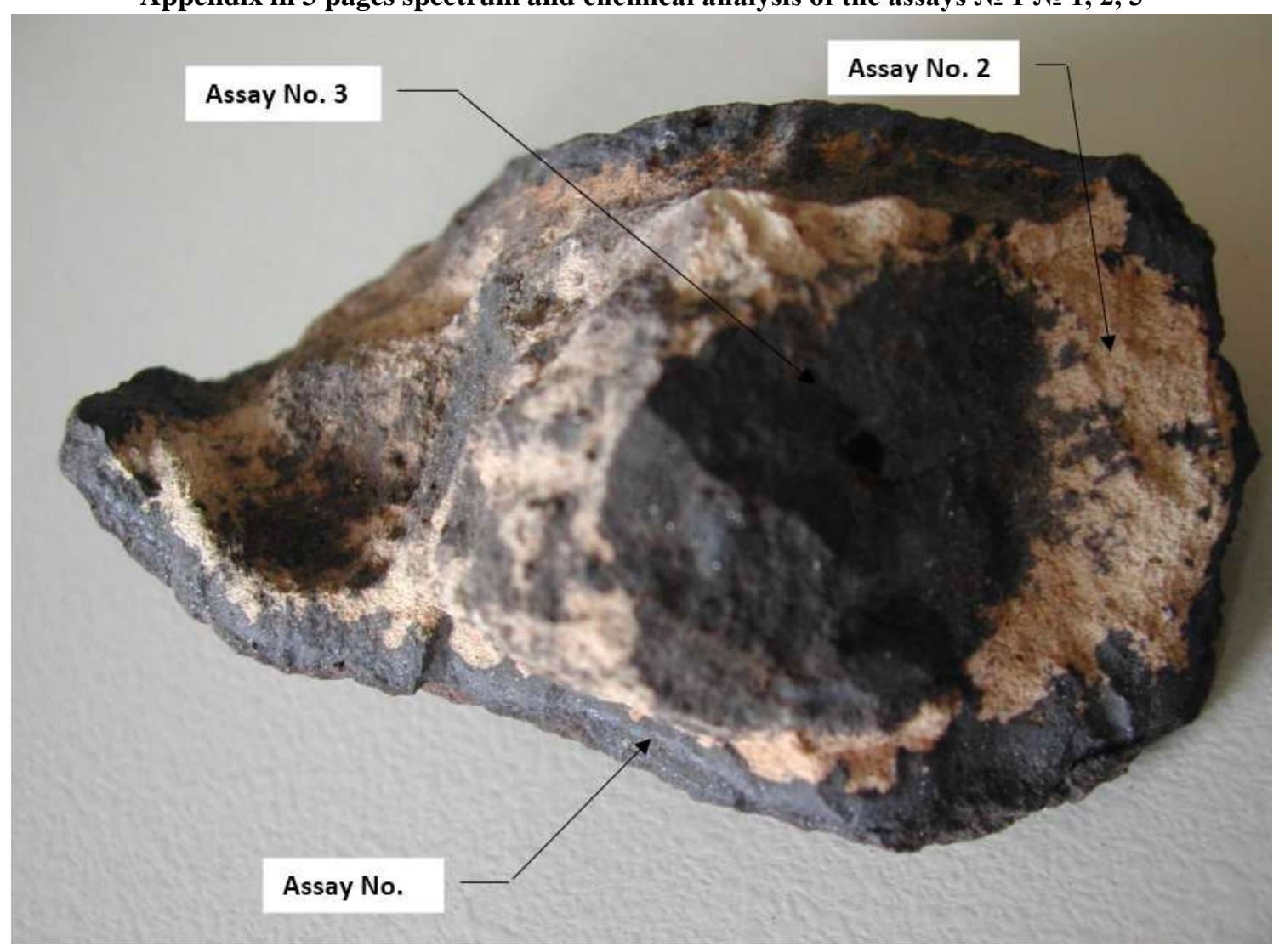

Assay No. 2 and 3 has beryllium (Be) $26 ? 94 \%$ and 13,81\%. There is no beryllium in assay 1. Oxygen (O), Silicium (Si) and manganese (Mn) is present in assay No. $1-57 \%, 16,13 \%$ and 19,11\%, but they are absent in assay No. 2 and 3. There is no ferrum $(\mathrm{Fe})$ in assay No. 2. Assay No. 1 does not have any carbon, but assay No. 2 and 3 it is $71 \%$ and $85 \%$ correspondingly. There is insignificant amount of aluminum $(\mathrm{Al})$, nickel $(\mathrm{Ni})$, kalium $(\mathrm{K})$. Calcium $(\mathrm{Ca})$ is absent. Different chemical composition is connected with the presence of cold fusion plasma, where transmutation of chemical elements into other occurs. Ball concretions formation is connected with the availability of electricity in the Earth crust. Electric discharge occurs inside the reservoir bed in various layers solutions (fluids), containing chemical elements dissolved in it. Such process is possible only with the availability of plasma of different form, having gravitation and magnetic field, processing layers' solutions and forming geological bodies of different composition. Cold fusion processes lead to the formation of various fields of fluid minerals. 


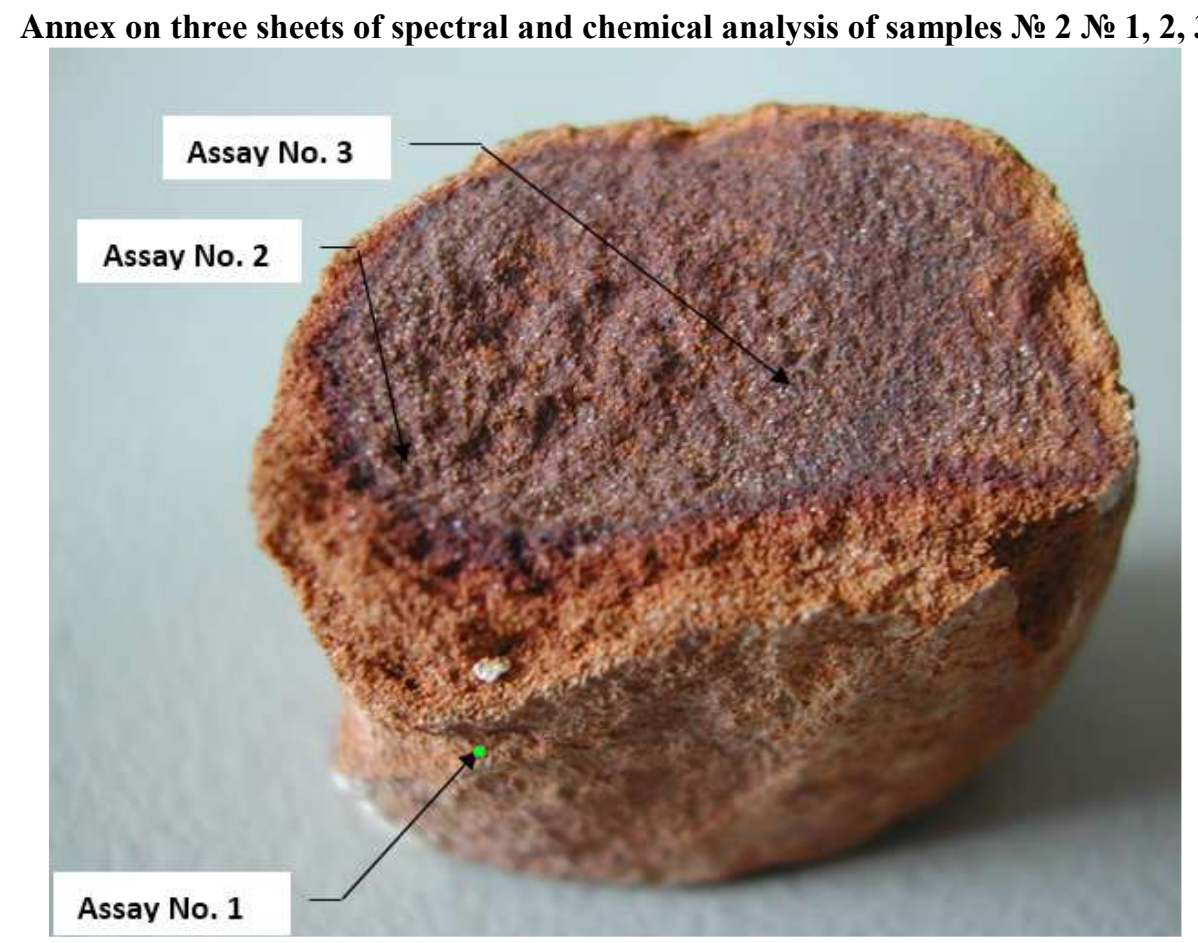

There is carbon in assay No. $1-17,73 \%$, it was not found in other assays. Oxygen is similar in all three assays and is $50 \%$. Silicium ( $\mathrm{Si}$ ) is $14 \%$ on average. Ferrum contents $(\mathrm{Fe})$ in assay No. 1 is $10,45 \%$, in assay No. 2 and 3 it is $33 \%$ and $27 \%$ correspondingly. There is also aluminum $(\mathrm{Al})$, titanium $(\mathrm{Ti})$, kalium $(\mathrm{K})$. There is calcium only in the third assay. Different chemical composition is connected with the presence of cold fusion plasma, where transmutation of chemical elements into other occurs. Ball concretions formation is connected with the availability of electricity in the Earth crust. Discharge occurs inside the reservoir bed in the form of spark and current impulse or there is constant direct current, caused by the difference of salt and minerals concentration in the bed solution. Such process is possible with the availability of plasma of different form, having gravitation and magnetic field, processing bed solutions and forming geological bodies of different construction. It is supposed that process of cold fusion occurs there and it leads to the formation of different polymetals fields, coals, geological materials and minerals.

The results of the experiments, shows a spherical formation of asphalt-tar substances. And of the oil received minor fraction of gasoline.

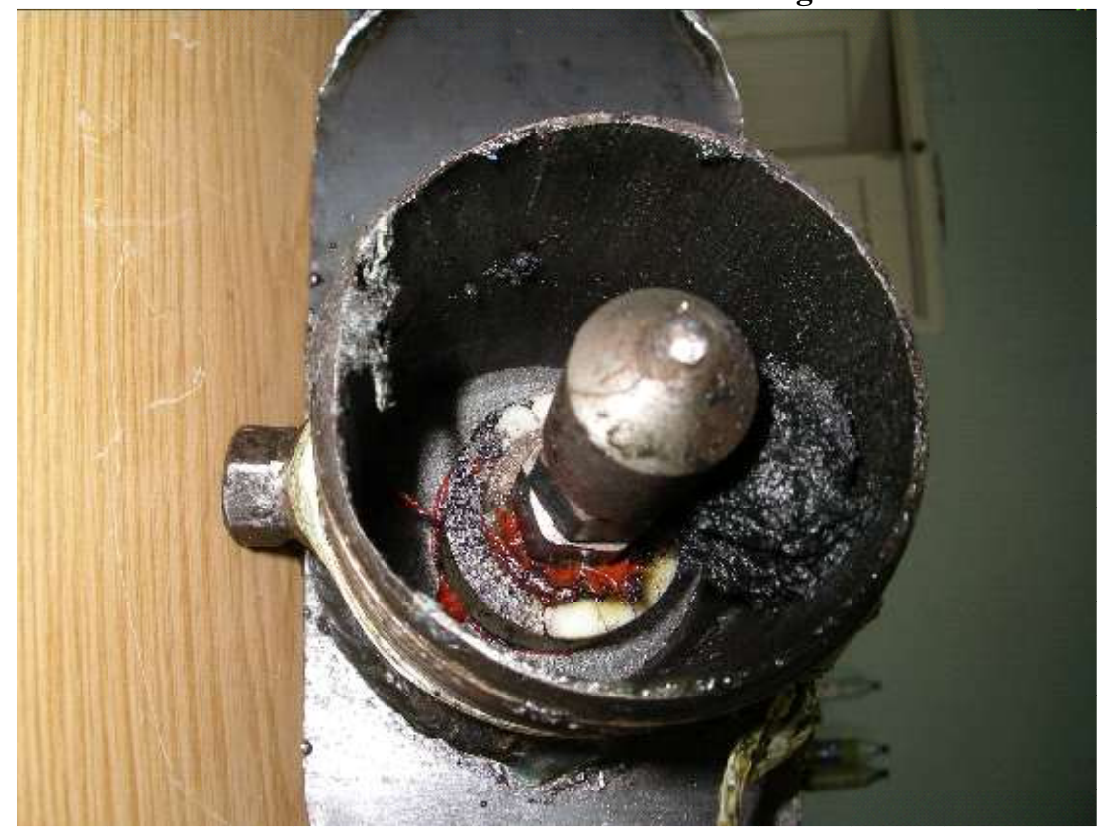


At the same time first testing experiments were carried out on the modeling of deposits sheets conditions: pressure and magnetic fields were created and electric discharges were used in the experimental reaction furnace. The scheme shows the result. Unfortunately element analysis was not completed but encouraging results on the process taking place inside such a simple reactor were received. Voltage was registered at the stator after initial exposure of electric discharges.

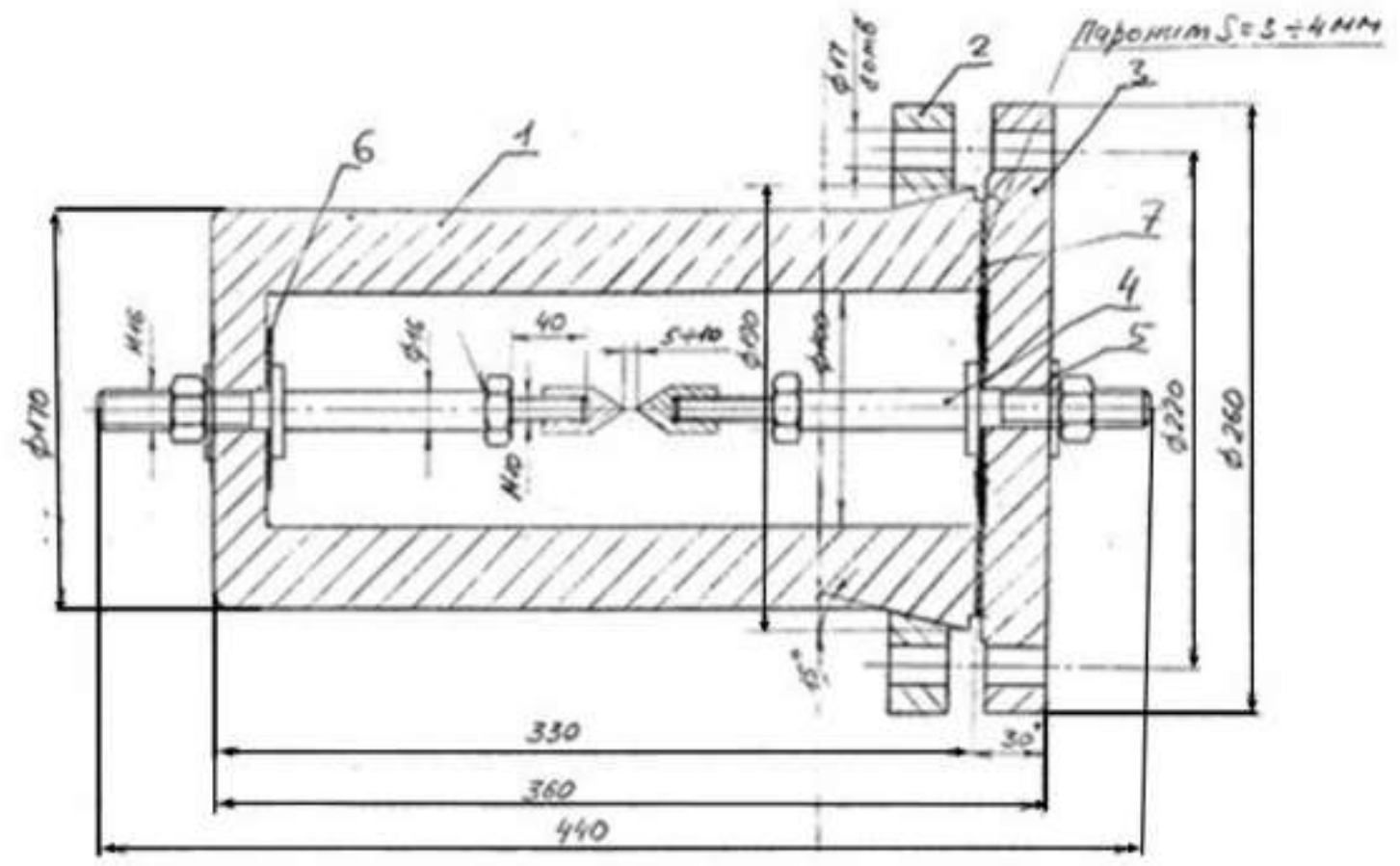

This electrical schematic diagram of the research to date, before this scheme is high-voltage laboratory was used to determine the gust of high voltage cables, where the ball air discharger.

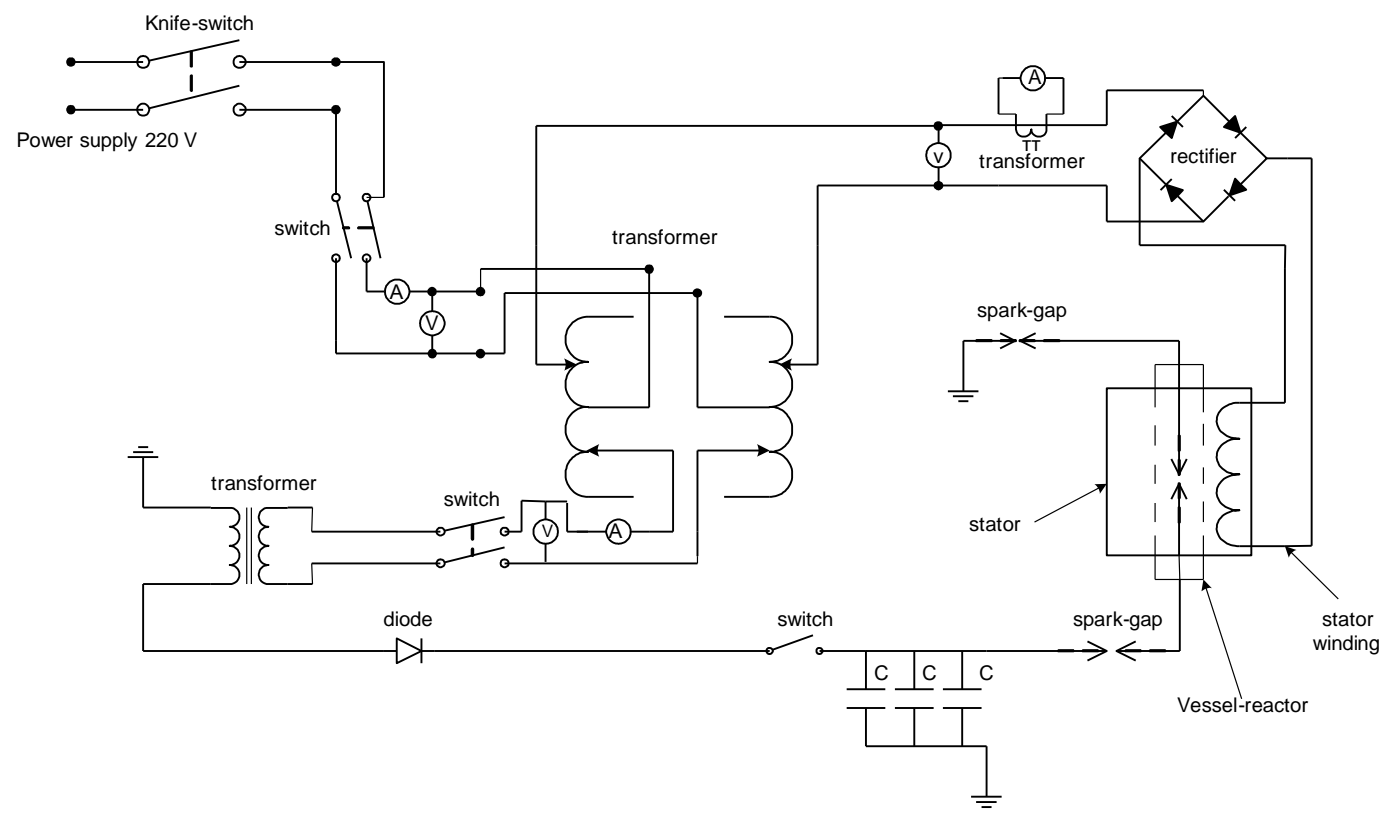

Also decided to create the same ball lightning, but in accordance with the massive ground and geological conditions in certain temperature and pressure conditions. 


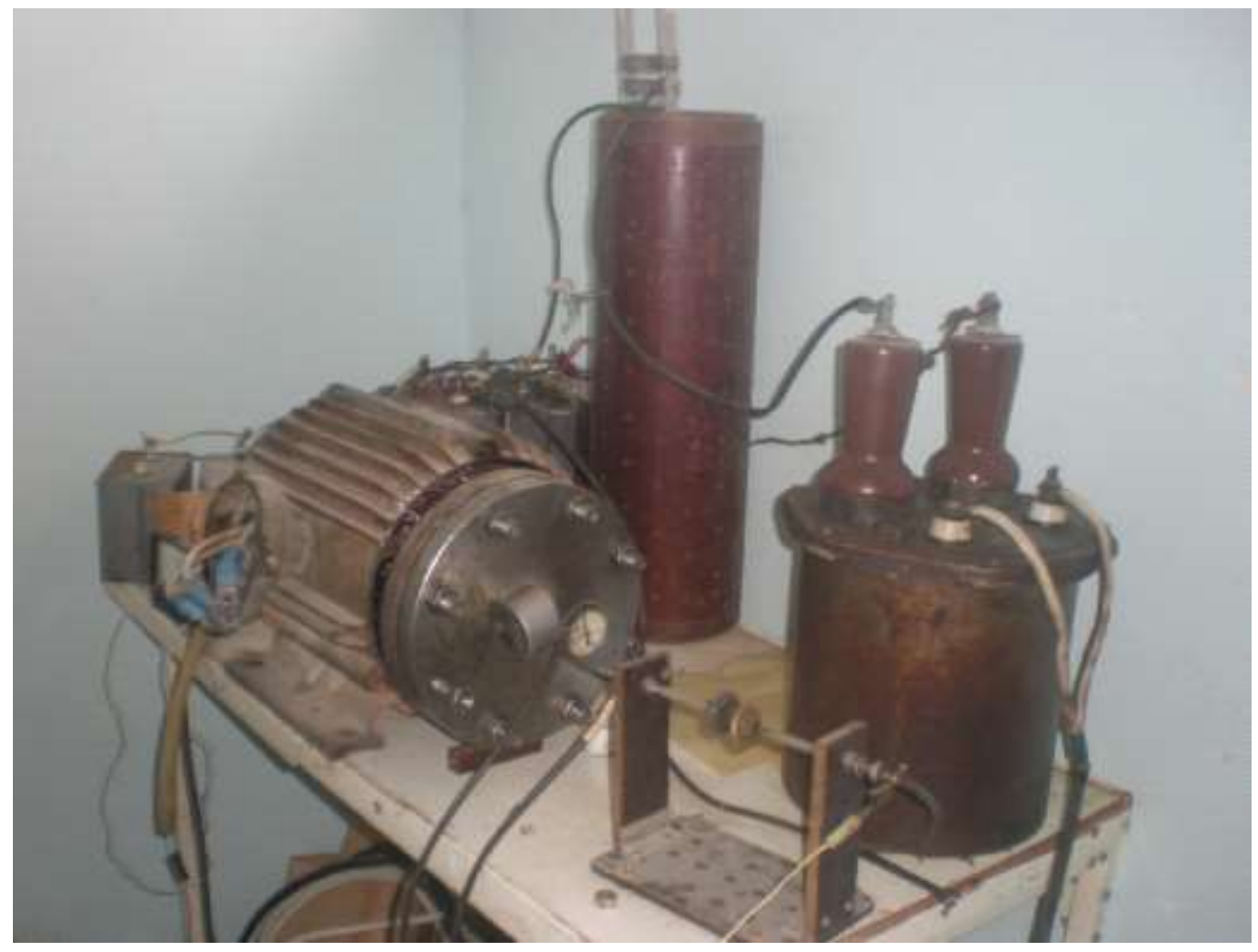

It can be clearly seen the spherical structure of the nodules, and they differ in chemical composition and can be seen visually

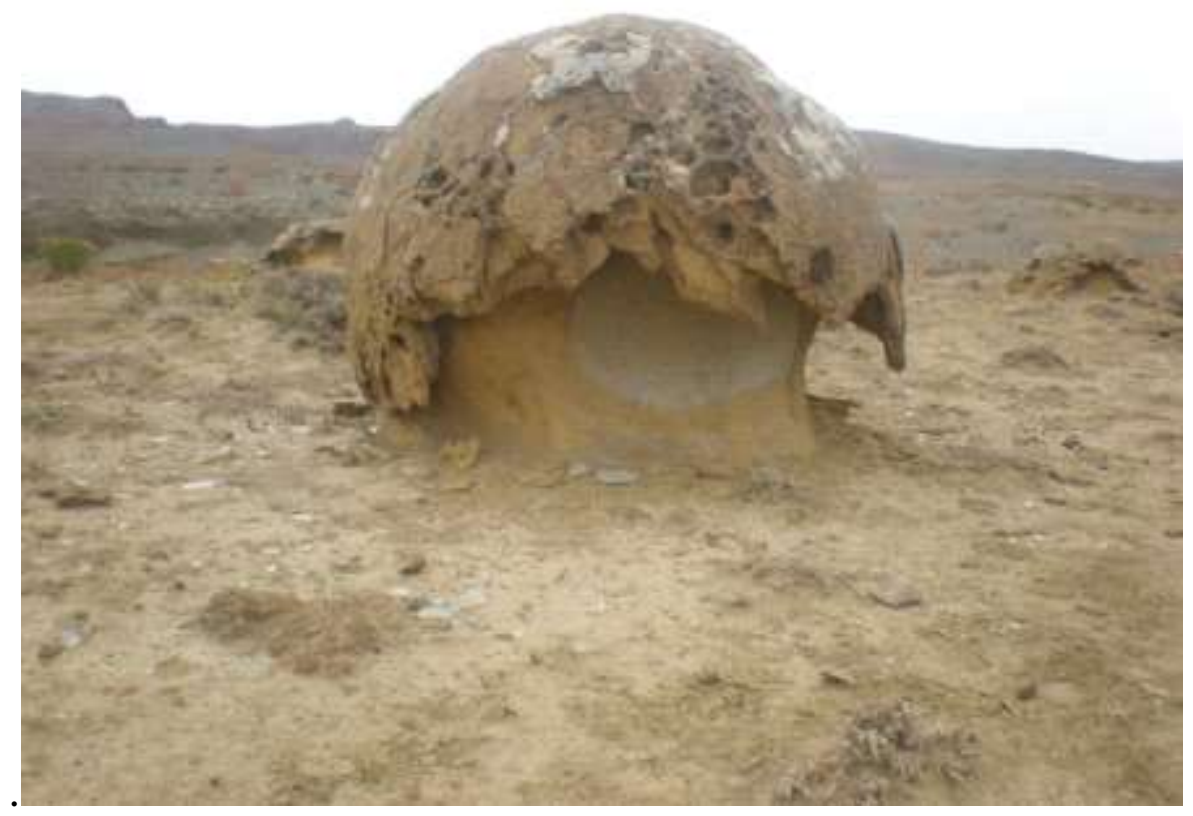



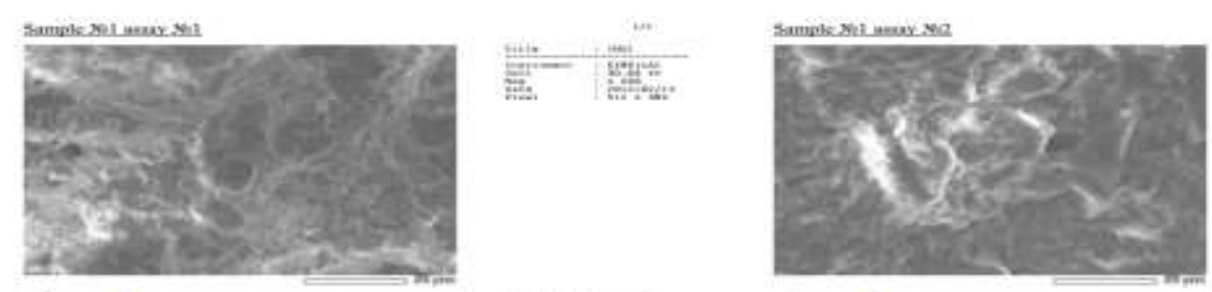

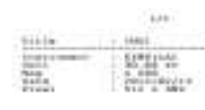
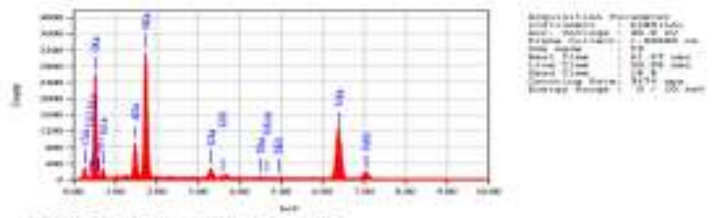

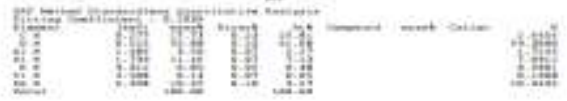

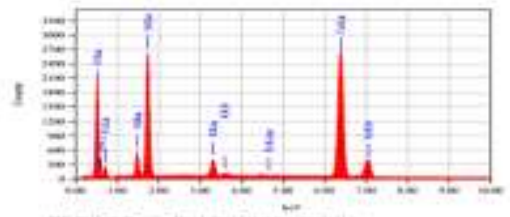

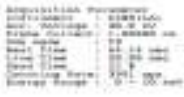

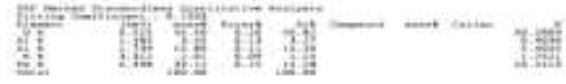
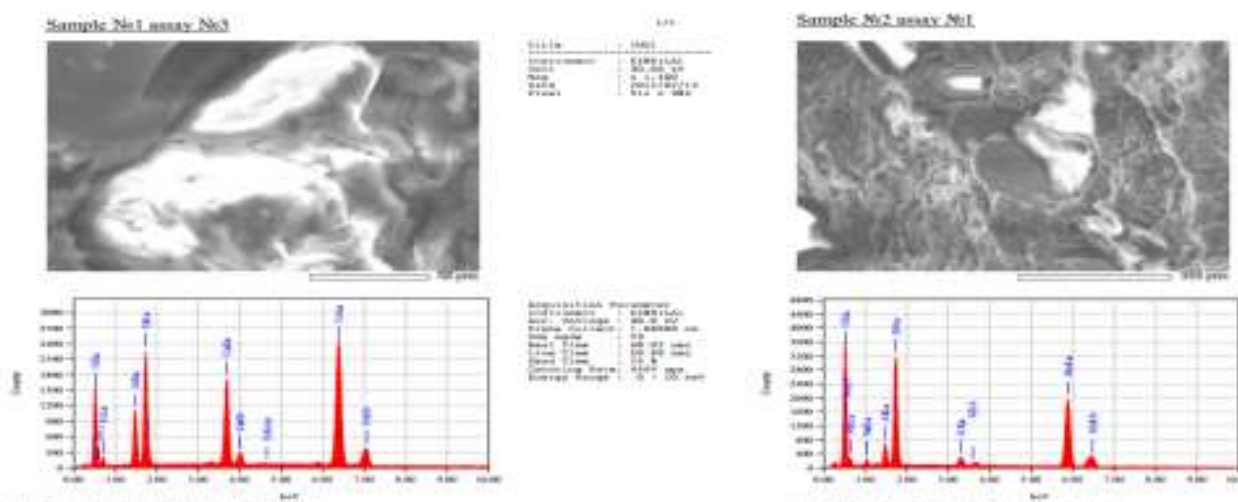

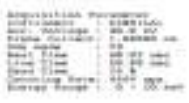

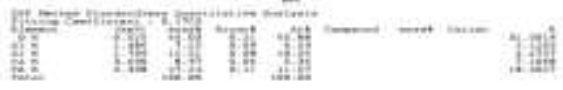

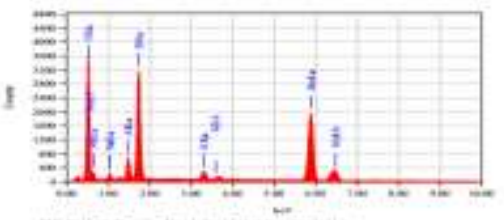

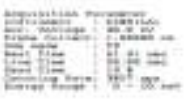

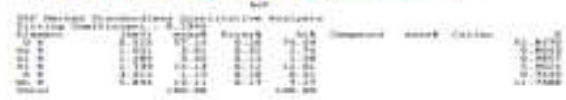
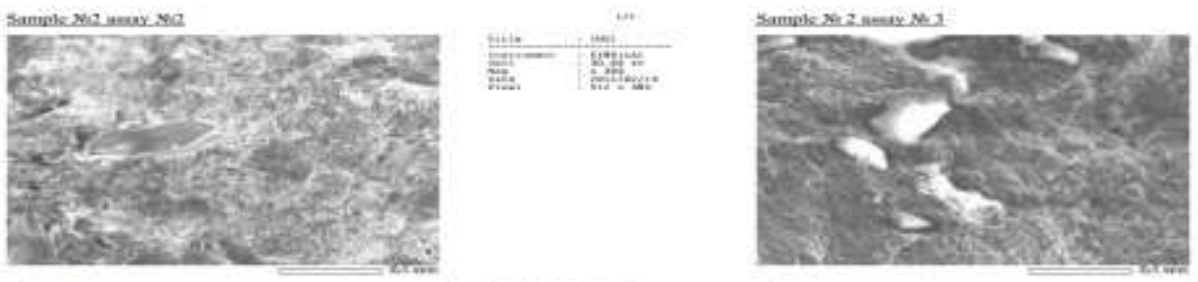

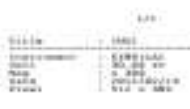

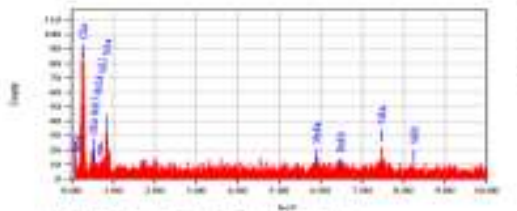

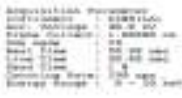

분

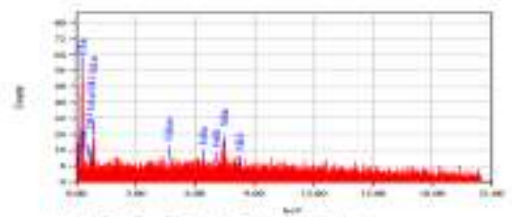

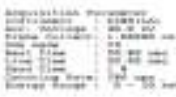

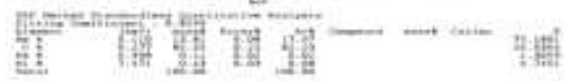

